\title{
The Place of Imaging in Ballistic Trauma about 54 Cases in Ouagadougou (Burkina Faso)
}

\author{
Boubakar Ouattara ${ }^{1,2,3,4}$, Siaka Ben Aziz Dao¹, Daouda Ouattara4, Soré Moussa Zanga², \\ Anick Ramdé1, Maurice Zida ${ }^{3}$, Rabiou Cissé1
}

\footnotetext{
${ }^{1}$ Radiology Department of the University Hospital Yalgado Ouédraogo (CHU-YO), Ouagadougou, Burkina Faso

${ }^{2}$ Radiology Department of the Charles De Gaulles Pediatric University Hospital, Ouagadougou, Burkina Faso

${ }^{3}$ Department of Surgery, CHU-YO/Medical Center of Camp General Aboubacar Sangoulé Lamizana (CMCGASL), Burkina Faso

${ }^{4}$ Radiology Department, CMCGASL, Burkina Faso

Email: `tibouattara2000@yahoo.fr, siakabenazizdao@gmail.com, ouaddaout@yahoo.fr, zasomo@yahoo.fr,

annick.ramde@yahoo.fr, zimaur@yahoo.fr, ciss.rabi@gmail.com
}

How to cite this paper: Ouattara, B., Dao, S.B.A., Ouattara, D., Zanga, S.M., Ramdé, A., Zida, M. and Cissé, R. (2022) The Place of Imaging in Ballistic Trauma about 54 Cases in Ouagadougou (Burkina Faso). Open Journal of Radiology, 12, 17-31.

https://doi.org/10.4236/ojrad.2022.121003

Received: November 26, 2021

Accepted: March 5, 2022

Published: March 8, 2022

Copyright $\odot 2022$ by author(s) and Scientific Research Publishing Inc. This work is licensed under the Creative Commons Attribution International License (CC BY 4.0).

http://creativecommons.org/licenses/by/4.0/

\begin{abstract}
Introduction: The purpose of this study was to determine the role of medical imaging in the management of ballistic trauma in the experience of the Burkina Faso Army Health Service. Methods: This was a retrospective, prospective, cross-sectional study of 54 cases of ballistic trauma that occurred in Burkinabe military personnel on Burkinabe territory between January 2016 and October 2019 and were managed by the Burkina Faso Army Health Service. Results: The mean age of the ballistic trauma victims was 28.9 years. The patients were all male. Multiple injuries were present in $19 \%$ of cases. The limbs were predominantly affected, followed by the trunk. Medical imaging was used both for the initial assessment and for the search for complications and follow-up after treatment. Standard radiography was the most commonly used modality followed by CT scan, particularly for the search for visceral lesions or for a more precise bone assessment. Ultrasound (E. FAST) was sometimes used. Magnetic resonance imaging was rarely used because of the ferromagnetic projectiles often present in ballistic trauma patients. Conclusion: Medical imaging has an important place in the management of military ballistic trauma.
\end{abstract}

\section{Keywords}

Ballistic Trauma, Radiography, Scanner, MRI, Burkina Faso

\section{Introduction}

Ballistic trauma (BT) is the consequence of the penetration into the body of a projectile (bullet, pellet, metallic shrapnel) coming from the envelope and/or the 
contents of an explosive device [1] [2]. They are the cause of serious lesions. These lesions are often multiple and immediately life-threatening due to blood spoliation, respiratory distress or lesion associations and, secondarily, due to infection [1] [3].

In Western countries, ballistic trauma is a public health problem and has increased in the last fifteen years [4]. This situation is favored by multiple factors such as the disintegration of the family structure, juvenile delinquency, the use of drugs, the dissemination of criminal acts by the mass media, and the easy access to weapons. In the United States, between thirty thousand $(30,000)$ and fifty thousand $(50,000)$ people die each year from ballistic trauma, which is the leading cause of death in the first two decades of life [5].

In civilian practice in developing countries, ballistic trauma is a rare reason for emergency room visits, essentially limited to hunting accidents, attempted homicide or suicide, or incidents of mishandling of their weapon by soldiers [1] [4].

In Africa, these ballistic injuries are relatively less frequent; Monka $\mathrm{M}$ et al. have reviewed 76 victims of the ammunition explosion of March 4, 2012 in Mpila-Brazzaville [6]; but they are of concern in some countries, particularly in South Africa and Nigeria [7] [8].

In Burkina Faso, although rare in civil practice, these BT are increasingly a concern due to political instability and the phenomenon of terrorism [9]. In the military environment, these traumas have increased significantly in recent years with the rise of terrorism, because the various military operations carried out to fight against this scourge record injury by firearms. In 2011, Zida and Col [8] had counted ninety-one (91) cases of gunshot wounds in Ouagadougou during the military insurrectionary crisis in Burkina Faso.

To understand the optimal management and treatment of gunshot wounds, an understanding of the lesion mechanisms due to penetrating agents and notions of lesion ballistics are necessary [10].

Ballistics is the science that studies the movements of a projectile launched by a firearm. A distinction is made between internal ballistics (inside the barrel of the weapon), intermediate ballistics (immediately outside the barrel), external ballistics (the trajectory of the projectile in the air) and terminal ballistics (when the projectile hits the target). When the target is a living being, terminal ballistics becomes lesion ballistics [11]. Weapons are therefore the starting point for lesion ballistics.

Weapons can be classified according to different characteristics; classification according to the mechanism of action seems more appropriate, as this influences the lesion mechanism. There are firearms (light weapons, heavy weapons, explosive weapons, compressed air weapons), bladed weapons, throwing weapons, weapons of mass destruction, non-lethal weapons.

High-energy trauma: the concept of ballistic injury

High-energy perforating trauma is the prerogative of firearms and explosive shrapnel or any other object propelled at high speed; the severity of an injury is 
directly related to the amount of kinetic energy lost in the tissue.

The constitution of the vulnating channel

The penetration of a projectile takes place in three phases.

- The entrance or neck.

- The bubble; this is the zone where the projectile produces the most effects. It is in this zone that the projectile tears and pushes back the tissues to the maximum, tilts spontaneously or disintegrates. The bubble contains 02 parts: The permanent cavity is due to the passage of the projectile lacerating the tissues on its trajectory and represents the damage directly objective at the exploration of the wound. This permanent cavity persists after the projectile has passed through and its size is proportional to its caliber. Moreover, its diameter increases from the point of impact to the exit due to the mushroom effect, which increases the diameter of the projectile almost instantaneously, but also due to the tilting of the projectile in the tissues or to a possible fragmentation of the bullet on contact with a bone [12].

The temporary cavity is the result of the propagation of shock waves perpendicular to the path of the projectile, distending and shearing the adjacent tissue. It also creates a vacuum within the cavity, causing foreign bodies to be sucked in from the point of entry, a potential source of infection. Its size depends on the amount of energy transferred, but also on the properties of the tissue crossed. Thus, a solid, inelastic tissue such as the liver will suffer more damage than a lung, which will be able to absorb more energy by distending without suffering significant damage.

This cavitation phenomenon may be responsible for lesions at a distance from the trajectory of the projectile, which is difficult to objectify during exploration and may go unnoticed [13].

- The exit: it is unique if the projectile has remained intact. It can be multiple if the bullet has fragmented with a main exit and secondary exits where the peripheral canals open. It has a crater shape, with the flesh forming a bead on its periphery. Its diameter is greater than the section of the projectile. The tissues around its periphery are lacerated. Inside are debris of bone or pieces of the internal organs injured.

The management of ballistic trauma is specific and multidisciplinary, mobilizing anesthesiologists, surgeons and radiologists [3] [9].

In the military environment, this care is provided by the "health support chain" from the units deployed in the field to the reference structures of the Armed Forces Health Service (SSA) of Burkina Faso. The aim of our study was to determine the place of medical imaging in this chain of care in the military environment.

\section{Methodology}

This was a descriptive, retrospective, prospective study of Burkinabe military personnel, victims of ballistic trauma on Burkinabe soil and cared for by the 
Health Service of the Armies of Burkina Faso, over the period from January 2016 to October 2019. We identified military victims of BT who had a medical record and/or were available for interview to reconstruct the patient's itinerary, radiological examinations performed, and time to imaging management since the occurrence of trauma. Military personnel with ballistic trauma after the start of the study were included on as we go along.

The study material included consultation and clinical records.

These were the registers in which the movements of patients were recorded, particularly the register of those injured in operations. In addition, we used clinical records when available, as well as operative reports.

For data collection we used a written, anonymous and confidential questionnaire. This questionnaire was previously tested on a sample of ten patients. The following variables were studied:

- Socio-demographic data: age, category (Non-commissioned Member, Noncommissioned Officer, Officer); gender, location of the trauma;

- Clinical data: circumstances, affected areas, hemodynamic status, respiratory status;

- Imaging data: modalities (ultrasound, X-ray, CT, MRI); time frame, structures that performed the examination;

- Lesion assessment: bone, joint, craniofacial, thoracic, abdominal, limb, vascular lesions;

- Treatment: methods, evolution;

- The data collected were entered and analyzed on a microcomputer using the Epi info software in its version 7.1.4.0fr;

- Radiological images were processed with RadiAnt software version 5.0.1.

\section{Results}

\subsection{General Data}

During the study period, 64 cases of ballistic trauma were recorded, 54 of which were retained for our study, the others being excluded for lack of exploitable archives. All victims were male and their average age was 28.9 years with extremes of 23 and 47 years. The majority of casualties (94\%) were from military theaters of operations, approximately $85 \%$ of injuries occurred during combat and $11 \%$ were accidental. Heavy weapons and improvised explosive devices were responsible for $68 \%$ of ballistic injuries.

\subsection{Type of Weapon}

The type of weapon involved could be specified for all the cases in our sample. For accidents and injuries that occurred during exercise, the weapon involved was specified.

In ambushes, these are Improvided Explosive Devices (IEDs). However, for heavy and light weapons, it is most often a deduction when the fight took place with a heavy weapon, a light weapon or both, because the projectiles are not al- 
ways found.

\subsection{Clinical Data}

Lesions were multifaceted and associated. The lesions were multiple in 19\% of cases, with a clear predominance of lower limb involvement (59\%) followed by upper limb involvement (42\%). Injuries to the cranioencephalic and neck ( $\mathrm{n}=$ $11)$, abdominal $(n=07)$, and thoracic $(n=06)$ levels were also noted, with trauma to the spine in two patients. Table 1 shows the distribution of patients according to lesion topography.

The injuries observed consisted of limb fractures, followed by soft tissue wounds without associated bone damage, but with the presence of splinters and metal projectiles in the injured.

\subsection{Imaging Data}

A variety of radiological investigations were performed for military BT patients after their clinical evaluation. Patients were sometimes explored by several medical imaging techniques. The following table (Table 2) shows the distribution of these examinations.

The imaging examinations performed contributed to the initial lesion assessment and then to the monitoring during treatment and the search for complications. Various lesions were described on imaging and materilized in Figures 1-6.

Most patients had been assessed for injury by imaging prior to their admission to the operating room.

Table 1. Lesion topography in ballistic trauma, $\mathrm{N}=54$.

\begin{tabular}{ccc}
\hline Topographie & Effectifs & Percentage (\%) \\
\hline Lower limbs & 32 & 59.25 \\
Upper limbs & 23 & 42.59 \\
Head and neck & 11 & 20.37 \\
Abdomen & 07 & 12.96 \\
Thorax & 06 & 11.11 \\
Thoracoabdominal & 04 & 7.69 \\
Spine & 02 & 3.84
\end{tabular}

Table 2. Distribution of medical imaging examinations performed, $\mathrm{N}=54$.

\begin{tabular}{ccc}
\hline Examinations & Numbers & Percentage (\%) \\
\hline Standard radiography & 51 & 94.44 \\
CT scan & 24 & 44.44 \\
Ultrasound & 3 & 5.55 \\
MRI & 1 & 1.85 \\
\hline
\end{tabular}




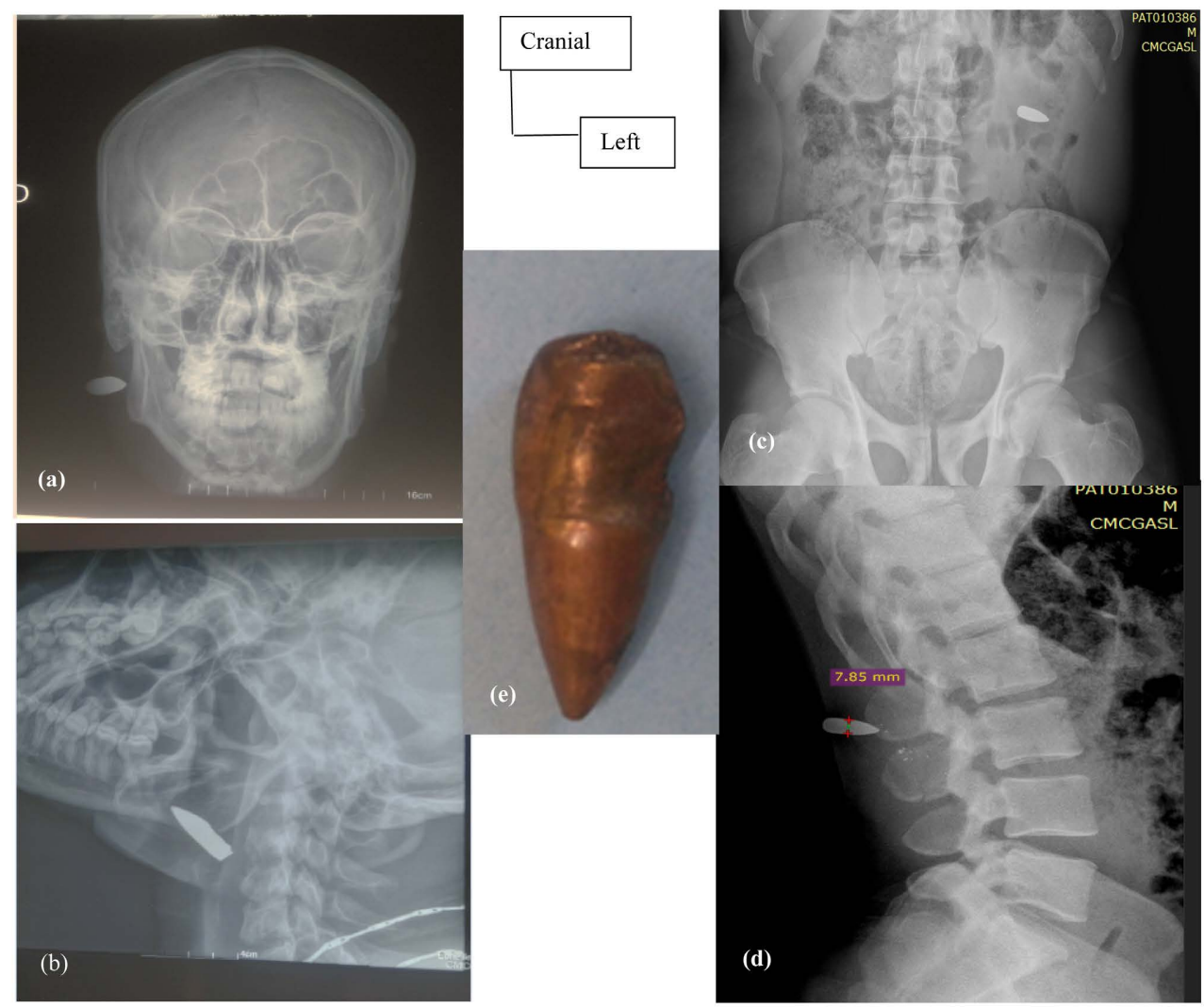

Figure 1. Radiological images that identified projectiles in different patients. 1) Frontal (a) and lateral (b) radiographs of the skull of a patient who suffered a BT during an attack and who presented wounds on the right subchin-chin level. Evidence of an oval metallic foreign body in the right pre-mandibular soft tissues related to a projectile, without any obvious recent post-traumatic bone lesion. 2) Front (c) and side (d) unprepared abdominal radiographs of a patient who suffered a BT during combat, showing the location of a projectile in the soft tissue of the back. In addition, we note a non-displaced linear fracture of the spinous process of L3. 3) Projectile extracted during trimming (e) in the patient whose radiographs are in (a) and (b).

30-year-old patient with thoracoabdominal contusion from ballistic trauma in whom a CT scan was performed (Figure 3 ).

Imaging had revealed vascular complications. These were false arterial aneurysms associated with arteriovenous fistulas in two soldiers exposed to an accidental grenade explosion. They had presented multiple soft tissue wounds without bone lesions. Having presented signs of appeal (iterative bleeding for one and thigh swelling for the other), they each underwent angioscanning of the lower limbs, the images of which follow (Figure 4 and Figure 5).

Imaging was also used in the postoperative monitoring of patients as well as in the evolutionary follow-up of lesions after treatment. Limb fractures were generally followed by standard radiography and parenchymal lesions by CT scan. The following images are illustrations (Figure 6).

A 32-year-old patient, victim of ballistic trauma to the left arm, who presented with an open fracture of the upper $1 / 3$ of the humerus, treated by trimming and internal osteosynthesis with Kirschner wires. 

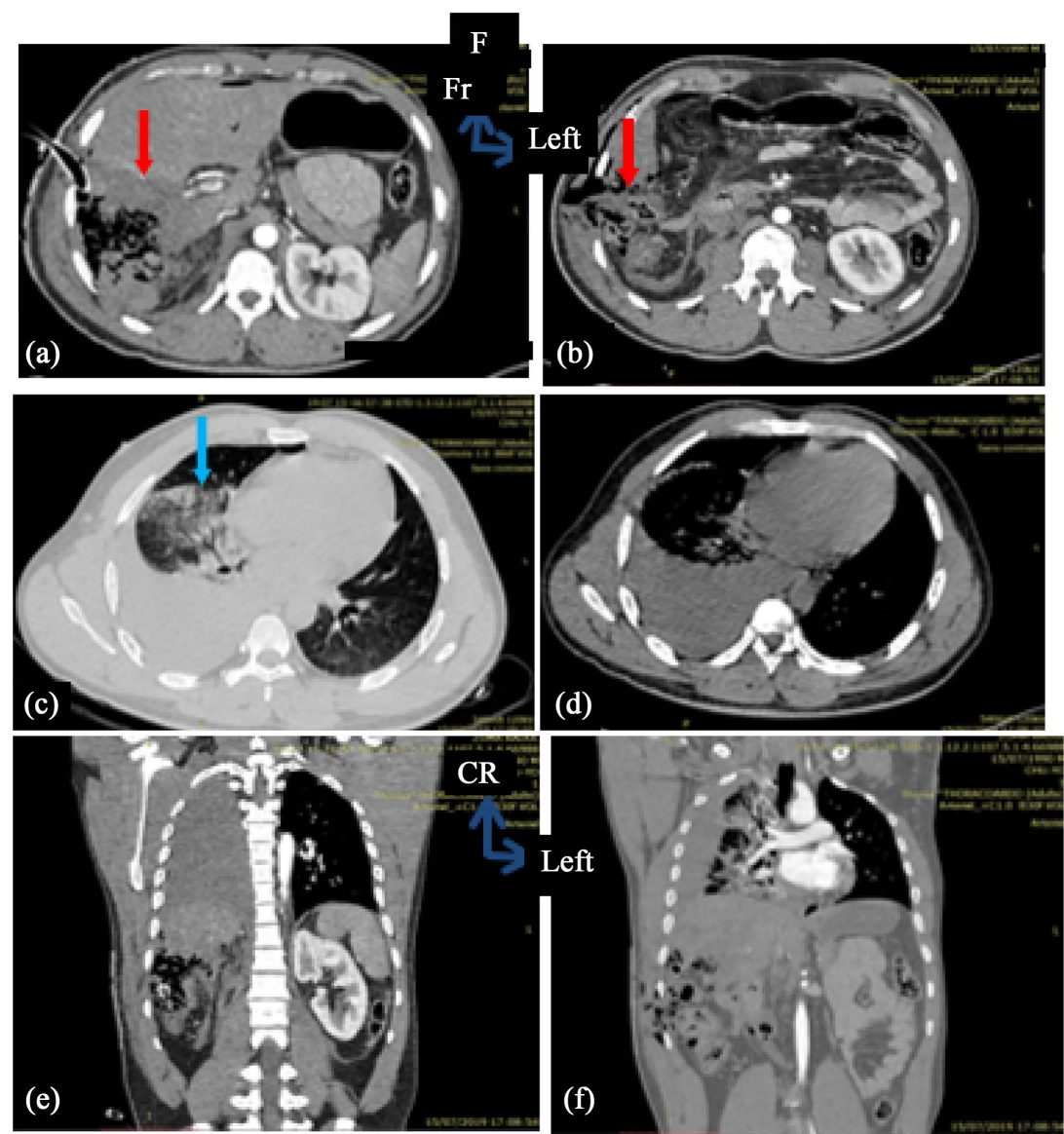

Figure 2. 30-year-old patient with thoracoabdominal contusion from ballistic trauma; CT axial slices with parenchymal windows in arterial phase ((a) and (b)), non-injected thoracic axial slices with parenchymal (c) and mediastinal (d) windows and coronal reconstructions with mediastinal (e) and parenchymal windows in arterial phase (f). These images objectify: 1) a hepatic contusion with laceration of segments VI and VII of the liver (red arrows in (a) and (b)), pneumoperitoneum and abdominal drain in place. 2) A large right hemothorax with passive pulmonary collapse and contusion (blue arrow) of the right pulmonary segment VII (para-cardiac) ((c), (d), (e), (f)). 3) In addition, there was a single functional left kidney.

\section{Discussion}

\subsection{Limitations of Our Study}

The interpretation of our results should take into account the contingencies and biases associated with this type of study, particularly the data collection.

The study took place in a military environment, an environment known for its rigor and discipline. In addition, this was a period of increasing terrorist acts with its corollary of victims but also of critics. Since most of the data was collected by interviewing the victim, some information could be concealed for fear of reprisals or, on the contrary, difficulties could be amplified to arouse emotion or improve the reactivity of the emergency services.

The psychological context of the recent trauma could also affect the accuracy of certain information. 

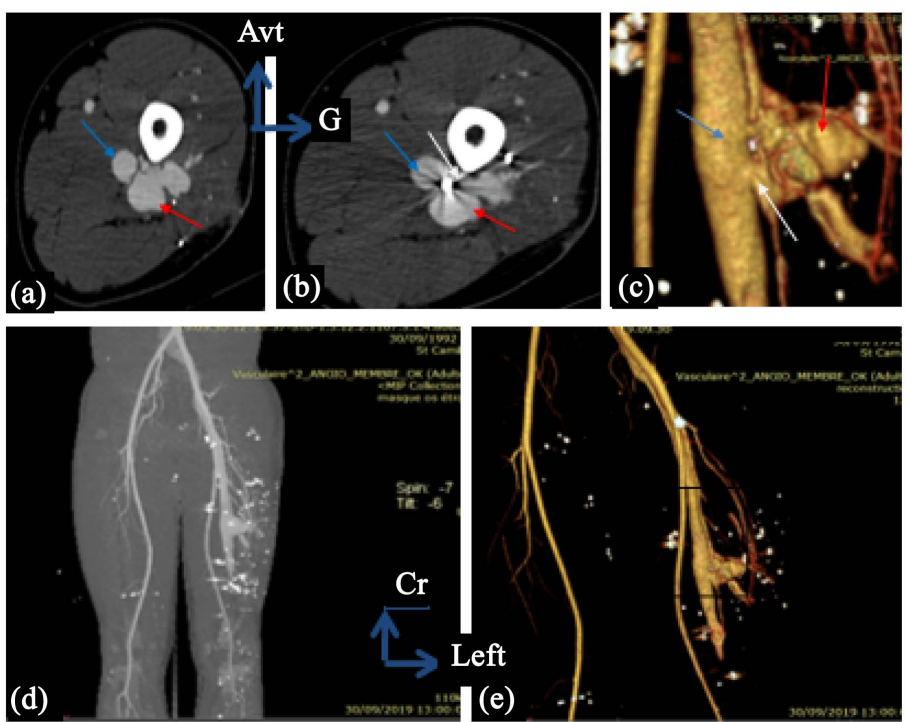

Figure 3. Angioscan of the left lower limb. Native axial sections ((a) and (b)). Coronal MIP (d) and VRT ((c) and (d)) reconstructions of the vascular axes of the same lower limb. We noted: 1) a saccular dilation of the left deep femoral artery at its terminal part in relation to a false aneurysm (red arrow). 2) The left deep femoral vein appeared dilated and enhanced at the arterial time with the same density as the artery (blue arrows) in relation to a false aneurysm. 3) There was an inclusion of a metallic foreign body (splinter) in the fistula with a fistula between the left deep femoral artery and vein (white arrows).

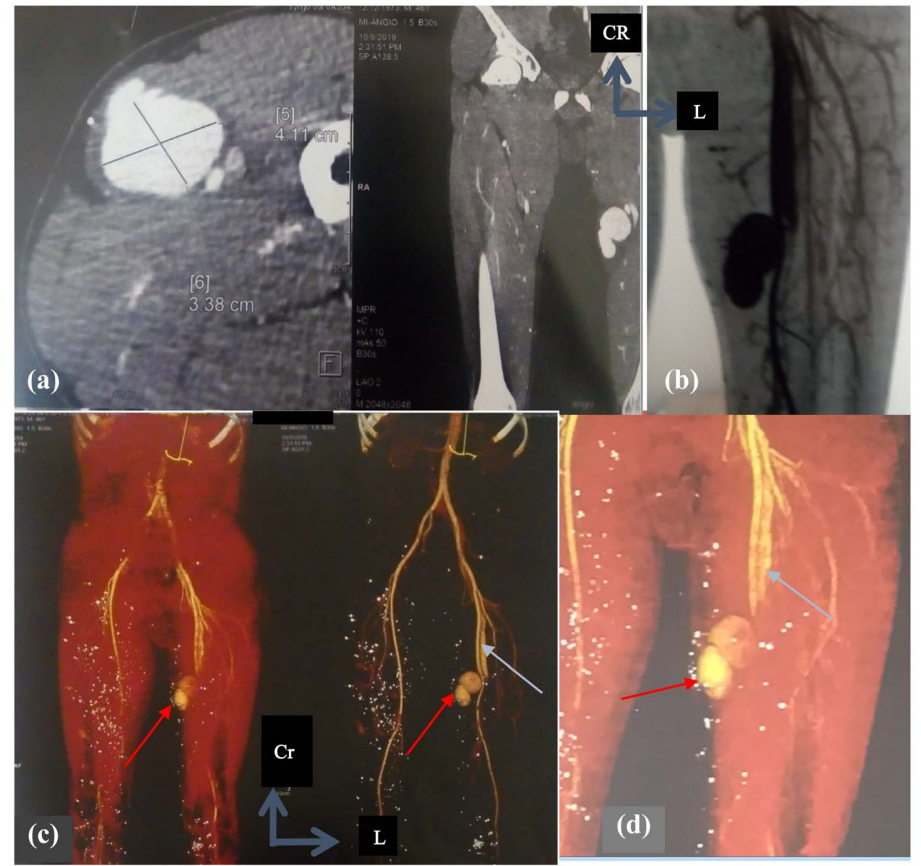

Figure 4. Angioscan of the lower limbs. Native axial slice and coronal reconstruction (a). Coronal MIP reconstruction of the lower limb vessels (b) and VRT reconstruction of the lower limbs ((c) and (d)). These images had objectified: 1) a saccular dilation of the left superficial femoral artery (red arrow) in the middle third of the thigh in relation to a false aneurysm. 2) A dilatation of the left superficial femoral vein (blue arrow) extended to the iliac veins with an enhancement on arterial time of the same density as that of the artery suggesting a fistula between the left superficial femoral artery and vein. 


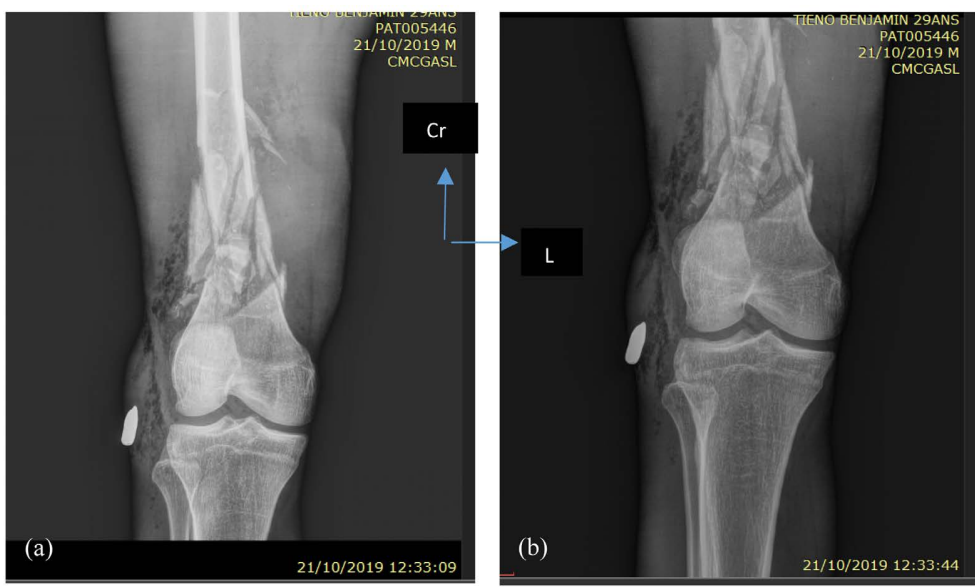

Figure 5. Evidence of limb fractures; patient with ballistic trauma to the right thigh. The radiographic examination revealed a minimally displaced supra condylar fracture with integrity of the knee joint relationships. Irregularity of the soft tissues with loss of substance was noted, as well as the presence of an oval metallic foreign body in the soft tissues of the external aspect of the knee, related to a projectile.

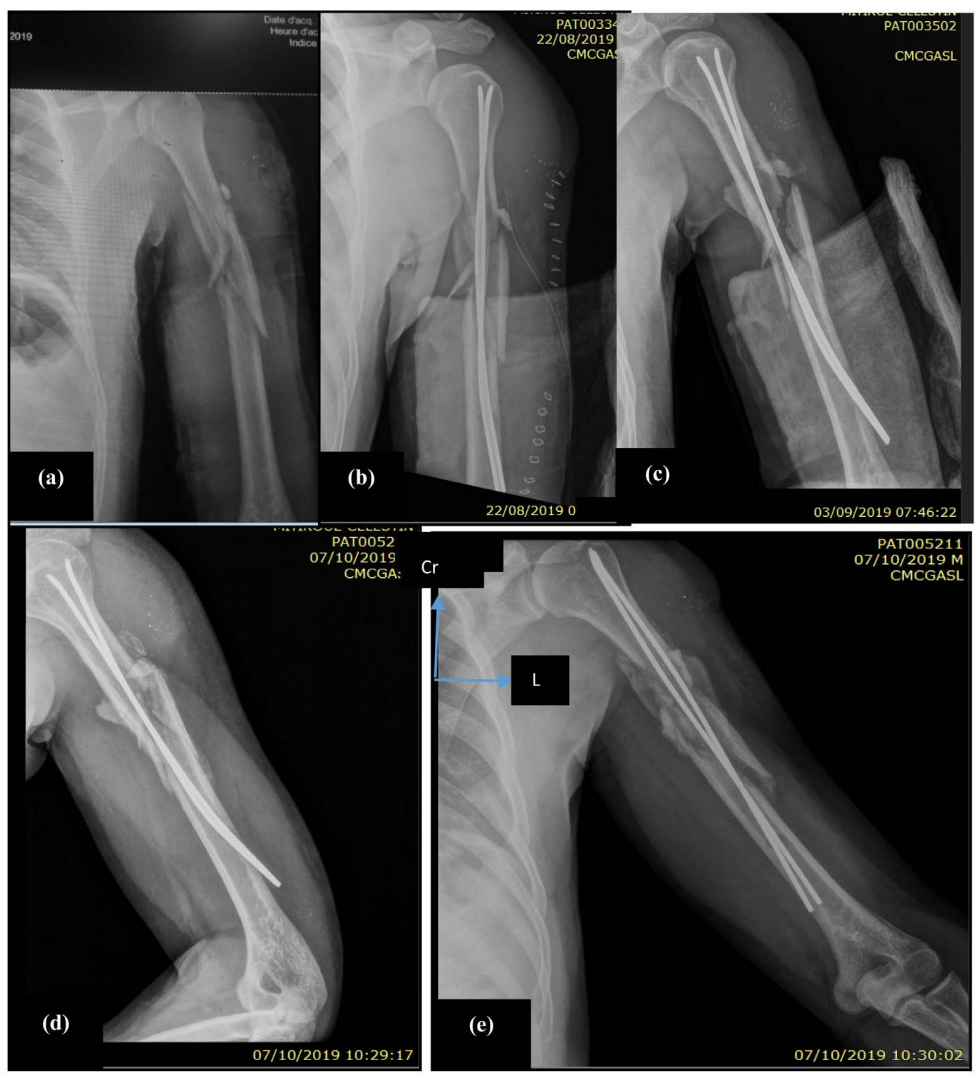

Figure 6. Initial and follow-up radiographic assessment under treatment. (a): initial radiograph showing the fracture of the upper $1 / 3$ of the humeral shaft; (b): immediate postoperative control radiograph with osteosynthesis material (pins) in place; (c): postoperative follow-up radiograph on day 12 showing the osteosynthesis material still in place, without secondary displacement of the fracture site; (d) and (e): control radiograph at $\mathrm{D} 45$ showing the bone callus information without secondary displacement or alteration of the osteosynthesis material. 
To minimize these different sources of bias, we explained to the patients the purpose of the present study in order to obtain their participation. They were also reassured about the confidentiality of the information they would provide.

\subsection{Comment}

Ballistic injuries were increasingly frequent in the military environment in Burkina Faso with the rise of the phenomenon of terrorism and the military operations to overcome this scourge.

Our study noted 64 cases over a period of four years, i.e. sixteen cases per year. This incidence is probably underestimated due to under-recording but also due to cases managed outside military health structures.

Military victims of ballistic trauma were male and predominantly young, with an average age of 28.9 years. This was consistent with the young age of the combatants and the findings of most studies of military ballistic trauma.

Indeed, the age of recruitment in our armies is twenty (20) years with an average duration of training of two years at the end of which the soldier is likely to be in theaters of operations. Similar findings were made in French and American soldiers injured in operations in Afghanistan and Iraq [14] [15] [16] with average ages of 28.5 and 27 years respectively.

Eighty-seven percent (87\%) of the injuries in our study occurred during combat. Similar circumstances are reported in the literature. Among American soldiers, explosions constituted $70 \%$ of the traumatic circumstances in the Iraq and Afghanistan conflicts [15]. As for the French wounded in Afghanistan, $74 \%$ had been injured during combat [17].

The type of weapon probably involved could be specified according to the circumstances in which the trauma occurred. For accidental injuries and those that occurred during exercises, certainty was established for the weapon involved. As for ballistic trauma during combat, the presumption is strongly established because the combatants could specify the type of weapons used by the enemy. Heavy weapons and IEDs are incriminated in $68 \%$ of ballistic injuries related to the enemy's modus operandi in this asymmetric warfare (ambushes followed by heavy and/or light weapons fire). This modus operandi is widely reported in the literature and our results are superior to those of the French Army Health Service, which reported $26 \%$ of IED-related injuries [17] [18]. The Americans found higher proportions, up to 97\%, in Iraq and Afghanistan [14] [15]. For Daghfous et al. in Tunisia, in a context of political unrest, all injuries were due to assault weapons [3].

The lesion topography revealed a predominance of limb injuries with approximately $63 \%$ of our patients. This predominance is constant in studies of ballistic injuries in both civilian and military practice [9] [17] [19] [20]. It can be explained, on the one hand, by the development and improvement of personal protective equipment (PPE) for combatants and, on the other hand, by the high mortality of cranioencephalic and thoracoabdominal injuries. Indeed, body armor and flak jackets as well as heavy combat helmets offer relative protection to the 
craniofacial and thoracoabdominal regions [11] [20] [21]. Most cranioencephalic and thoracoabdominal injuries are sources of hemodynamic and/or respiratory instability, often leading to death on the battlefield or during evacuation. Moreover, the predominance of such injuries is reported in the literature in Killed In Action (KIA) and Dead Of Wounds (DOW) [4].

In the context of military BT, multiple injuries are very frequent and have been consistently reported by authors [2] [9] [16] [19] [20]. Nineteen patients in our study (36\%) had multiple injuries, often combining visceral contusion and limb fractures. Wounded war victims of terrorist actions often present concomitantly blast lesions, polycriblage (lesions secondary to the explosion due to the projection of various debris) and burns, hence their multiple nature [14] [17] [18].

The injury assessment revealed a predominance of limb fractures with more than $60 \%$ of the injured. This finding is consistent with the predominance of limb injuries and is comparable to the data in the literature, both in civilian and military practice [2] [6] [17]. Visceral injuries, dominated in our series by abdominal contusions (7\%) followed by thoracic trauma with a parenchymal contusion, were reported in higher proportions by other authors [2] [14] [17].

Two casualties, all exposed to an accidental grenade explosion, had secondary arteriovenous fistulas associated with a false arterial aneurysm. These lesions are due to the blast and are secondary type lesions. Vascular lesions are often found during ballistic trauma. Daghfous et al. found two cases of vascular lesions in their series of 83 patients, including one case of arteriovenous fistula associated with an arterial wound. In the literature, hemorrhage from arterial wounds is the first cause of death in ballistic trauma patients [2] [14] [20].

Imaging has been widely used for the benefit of military victims of ballistic trauma and especially for hemodynamically stable casualties.

Imaging was used to assess the lesion and the choice of modalities was made taking into account the clinical data. FAST ultrasound is of great help in the surgical decision, which should not be delayed under any circumstances.

Almost all modalities were involved. It was requested both in the initial evaluation, the search for secondary complications as well as in the post-treatment monitoring.

Almost all patients had undergone standard radiography. It had been performed as a first line of defence in $94 \%$ of them to look for projectiles, splinters and bone lesions, whatever the area affected. In limb trauma, it is essential and is most often sufficient for the bone assessment. The exploration must include two orthogonal incidences. Concordant findings have been made by various authors in both civilian and military practice [2] [6] [9].

The CT scan was the most frequently performed examination after the standard X-ray, either in search of cranioencephalic or visceral lesions in the case of thoraco-abdominal contusions, or as a second-line examination for a more precise assessment of bone lesions. It was also used to determine the trajectory of the projectile and to search for lesions of the vascular axes of the lower limbs. In Tu- 
nisia, Daghfous et al. had used CT for the same indications. Indeed, the literature reports a good sensitivity of CT in the detection of lesions [3] [22] [23]. CT appears to be essential in the assessment of cranioencephalic firearm injuries and in ballistic spinal injuries, where it can be used to assess the contents of the spinal canal as well as any associated lesions [24].

In addition to CT, E. FAST (Extended FAST) ultrasound is widely practiced in the management of trunk TB for its sensitivity in detecting peritoneal, pleural and/or pericardial fluid effusions [16] [25]. In our study, the use of this modality had allowed on two occasions to indicate a laparotomy by objectifying a hemoperitoneum. Daghfous and Col in Tunisia had not performed any ultrasound, having used either CT or exploratory surgery with a negative surgery rate of $15 \%$ to $25 \%$ [2]. Several authors recommend a popularization of the practice of E. FAST ultrasound, which can be integrated into a strategy of non-operative management of thoracoabdominal trauma, with armed surveillance [16] [25] [26].

MRI was only used in one patient in our study to look for spinal cord injuries. Indeed, the context of ballistic trauma considerably limits the indications of MRI due to the possible presence of ferromagnetic projectiles with a risk of secondary aggravation of lesions by migration of these projectiles [24]. In the literature, this modality is rarely used for the exploration of ballistic trauma for the above-mentioned reasons and also because of the relatively long duration of the examination as well as the conditioning of the patient which may include metallic material [24] [27] [28].

These imaging examinations were performed within an average time of 27 hours with extremes of 2 hours and 192 hours. This average delay is relatively long when one considers the predominance of limb injuries. These lesions are classified in the battlefield in the U2 category, for which management can be delayed for up to 18 hours [29].

Casualties in the Eastern Zone had an average turnaround time of 16 hours. This time was less than 10 hours for the majority of casualties recorded during an operation where health support was well structured and imaging was performed at a Regional Hospital near the theater of operations. On the other hand, for the North and West zones, the delays were longer, with respective averages of 32 and 36 hours, probably due to the inaccessibility of these zones by road and the inadequacy of the air medical evacuation means used there.

\section{Conclusion}

Imaging has played an important role in the management of ballistic trauma, both for the initial assessment, the search for secondary complications and the follow-up of the evolution under treatment. Standard X-rays were essential for the assessment of limb trauma and CT scans are essential for the assessment of cranioencephalic, thoracoabdominal and vertebro-medullary injuries. MRI was very rarely used in the context of ballistic trauma, its main indication being the search for spinal cord injuries. It is then necessary to ensure the absence of con- 
traindications. Finally, the E. FAST ultrasound could constitute in our context an excellent tool for orientation and monitoring of thoraco-abdominal trauma and should be feasible by the military physicians of the front.

\section{Conflicts of Interest}

The authors declare that they have no ties of interest.

\section{Informed Consent and Confidentiality of Data}

The authors declare that the article contains no personal data that could identify the patient or subject.

\section{References}

[1] Ammirati, C.H. (2000) Stratégie de prise en charge extrahospitalière d'un polytraumatisé. Conférences d Actualisation 2000: 42ème Congrès national d anesthésie et de réanimation, édition avec CD-ROM, Elsevier Masson, Paris, 389-408.

[2] Daghfous, A., Bouzaïdi, K., Abdelkefi, M., et al. (2015) Contribution of Imaging in the Initial Management of Ballistic Trauma. Diagnostic and Interventional Imaging, 96, 45-55. https://doi.org/10.1016/j.diii.2014.02.012

[3] Ro, T., Murray, R., Galvan, D. and Nazim, M.H. (2015) Atypical Gunshot Wound: Bullet Trajectory Analyzed by Computed Tomography. International Journal of Surgery Case Reports, 14, 104-107. https://doi.org/10.1016/j.ijscr.2015.07.023

[4] Cavazos, J.C., Palacios-Zertuche, J., Reyna-Sepúlveda, F., Álvarez-Villalobos, N., Alatorre-López, L. and Muñoz-Maldonado, G. (2017) Epidemiology of Gunshot Wounds in the University Hospital "Dr. José Eleuterio González" of the Autonomous University of Nuevo León. Cirugía y Cirujanos (English Edition), 85, 41-48. https://doi.org/10.1016/j.circen.2016.12.013

[5] Stefanopoulos, P.K., Hadjigeorgiou, G.F., Filippakis, K. and Gyftokostas, D. (2014) Gunshot Wounds: A Review of Ballistics Related to Penetrating Trauma. Journal of Acute Disease, 3, 178-185. https://doi.org/10.1016/S2221-6189(14)60041-X

[6] Monka, M., Zaka Moukala, C.D., Bilongo-Bouyou, A. and Moyikoua, A. (2016) Prise en Charge Précoce des Traumatismes par Explosion de Munitions au CHU de Brazzaville. À Propos de 76 Cas. Health Sciences and Disease, 17, 20-22.

[7] Daban, J.L., Peigne, V., Boddaert, G., et al. (2012) Traumatisme pénétrant et balistique. Conférence dActualisation, Société Française dAnesthésie Réanimation (SFAR), Paris, 2012, 1-16.

[8] Bell, R.S., Mossop, C.M., Dirks, M.S., Stephens, F.L., Mulligan, L., Ecker, R., et al. (2010) Early Decompressive Craniectomy for Severe Penetrating and Closed Head Injury during Wartime. Neurosurgical Focus, 28, E1. https://doi.org/10.3171/2010.2.FOCUS1022

[9] Zida, M., Diallo, O., Zan, A. and Traoré, SS. (2013) Les plaies par armes à feu lors de la crise insurrectionnelle des militaires en 2011 à Ouagadougou (Burkina Faso). Revue International des Sciences Médicales, 15, 91-94.

[10] Pinto, A., Russo, A., Reginelli, A., Iacobellis, F., Di Serafino, M., Giovine, S., et al. (2019) Gunshot Wounds: Ballistics and Imaging Findings. Seminars in Ultrasound, CT and MRI, 40, 25-35. https://doi.org/10.1053/j.sult.2018.10.018

[11] Voiglio, E.J. and Caillot, J.L. (2008) Balistique lésionnelle: De ses origines à nos jours. La Revue du Carum, 23, 4-6. 
[12] Stefanopoulos, P.K., Filippakis, K., Soupiou, O.T. and Pazarakiotis, V.C. (2014) Wound Ballistics of Firearm-Related Injuries-Part 1: Missile Characteristics and Mechanisms of Soft Tissue Wounding. International Journal of Oral and Maxillofacial Surgery, 43, 1445-1458. https://doi.org/10.1016/j.ijom.2014.07.013

[13] Canseco Cavazos, J., Palacios-Zertuche, J., Reyna-Sepúlveda, F., Álvarez-Villalobos, N., Alatorre-López, L. and Muñoz-Maldonado, G. (2017) Epidemiología de las lesiones por proyectil de arma de fuego en el Hospital Universitario "Dr. José Eleuterio González” de la Universidad Autónoma de Nuevo León. Cirugía y Cirujanos, 85, 41-48. https://doi.org/10.1016/j.circir.2016.05.015

[14] Holcomb, J.B., McMullin, N.R., Pearse, L., Caruso, J., Wade, C.E., Oetjen-Gerdes, L., et al. (2007) Causes of Death in U.S. Special Operations Forces in the Global War on Terrorism: 2001-2004. Annals of Surgery, 245, 986-991.

[15] Kelly, J.F., Ritenour, A.E., McLaughlin, D.F., Bagg, K.A., Apodaca, A.N., Mallak, C.T., et al. (2008) Injury Severity and Causes of Death From Operation Iraqi Freedom and Operation Enduring Freedom: 2003-2004 Versus 2006. The Journal of Trauma: Injury, Infection, and Critical Care, 64, S21-S27.

[16] Udobi, K.F., Rodriguez, A., Chiu, W.C. and Scalea, T.M. (2001) Role of Ultrasonography in Penetrating Abdominal Trauma: A Prospective Clinical Study. The Journal of Trauma: Injury, Infection, and Critical Care, 50, 475-479.

[17] Pasquier, P., de Rudnicki, S., Donat, N., Auroy, Y. and Merat, S. (2011) Type et épidémiologie des blessures de guerre, à propos de deux conflits actuels: Irak et Afghanistan. Annales Françaises d'Anesthésie et de Réanimation, 30, 819-827. https://doi.org/10.1016/j.annfar.2011.05.018

[18] Poyat, C., Boutonnet, M., Pelée de Saint Maurice, G., Ausset, S., Daban, J.L. and Blot, R.M. (2017) Profil des blessés de guerre Français en Afghanistan : expérience du service de santé des armées sur la période 2001-2010. Anesthésie \& Réanimation, 3, 403-412. https://doi.org/10.1016/j.anrea.2017.07.010

[19] Fabeck, L., Hock, N., Goffin, J. and Ngatchou, W. (2017) Notions de balistique et prise en charge des plaies par balle au niveau des members. Revue Médicale de Bruxelles, 38, 474-481.

[20] Nau, A., Ewaroquier, A., Ponchel, C.H., Becret, A. and Peytel, E. (2008) Traumatismes balistiques Actualités sur les lésions traumatiques de guerre. La Revue du Carum, 23, 17-19.

[21] Lamour, O., Tillant, D., Teboul, A. and Laborie, J.M. (2004) Biomécanique des traumatismes balistiques. Elsevier SAS, Paris.

[22] MacFarlane, C. (2002) Aide Memoire for the Management of Gunshot Wounds. Annals of the Royal College of Surgeons of England, 184, 230-233.

[23] Kieser, D.C., Carr, D.J., Leclair, S.C., Horsfall, I., Theis, J.C. and Swain, M.V. (2013) Gunshot Induced Indirect Femoral Fracture: Mechanism of Injury and Fracture Morphology. Journal of the Royal Army Medical Corps, 159, 294-299.

[24] Jourdan, P., Breteau, J.P., Wolff, P., Jourdan, P., Breteau, J.P. and Volff, P. (1994) Spinal Cord Injuries Caused by Extraspinal Gunshot. A Historical, Experimental and Therapeutic Approach. Neurochirurgie, 40, 183-195.

[25] Von Kuenssberg Jehle, D., Stiller, G. and Wagner, D. (2003) Sensitivity in Detecting Free Intraperitoneal Fluid with the Pelvic Views of the FAST Exam. The American Journal of Emergency Medicine, 21, 476-478. https://doi.org/10.1016/S0735-6757(03)00162-1

[26] Pryor, J.P., Reilly, P.M., Dabrowski, G.P., Grossman, M.D. and Schwab, C.W. (2004) 
Nonoperative Management of Abdominal Gunshot Wounds. Annals of Emergency Medicine, 43, 344-353.

[27] Debien, B. and Lenoir, B. (2004) Traumatismes balistiques du thorax. Elsevier, Paris, 515-532.

[28] Manthey, D.E. and Nicks, B.A. (2008) Penetrating Trauma to the Extremity. The Journal of Emergency Medicine, 34, 187-193.

[29] Khair, H. (2017) Intérêt de la balistique lésionnelle dans la chirurgie de guerre. Thèse de Doctorat en médecine. University Cadi Ayyad, Faculté de médecine et de pharmacie de Marrakech, $\mathrm{N}^{\circ} 87,180 \mathrm{p}$. 